\title{
A MARGEM DE INTERPRETAÇÃO DOS TRATADOS
}

\author{
Eneida Orbage de Britto Taquary ${ }^{1}$ \\ Catharina Orbage de Britto Taquary ${ }^{2}$
}

RESUMO: Analisa a problemática de interpretação dos tratados com fundamento na Convenção de Viena sobre Direito dos Tratados e a aplicação da margem de apreciação como método de interpretação ou método de reduzir as diferenças culturais, determinando uma diminuição da autoridade moral e jurídica dos Tribunais Internacionais de Direitos Humanos, deixando ao Estado a discricionariedade de limitar o exercício de direitos e liberdades. Objetiva conhecer as regras de interpretação dos tratados baseadas na Convenção de Viena e a técnica da margem de apreciação. O método utilizado consiste na revisão bibliográfica e na referência a casos apreciados pelos tribunais de Direitos Humanos.

PALAVRAS-CHAVE: Margem de Apreciação dos Tratados; Convenção de Viena sobre Direito dos Tratados; Pacta Sund Servanda; Deferência judicial; Flexibilidade Normativa.

\section{THE MARGIN OF INTERPRETATION OF THE TREATIES}

ABSTRACT: It analyzes the question of the interpretation of treaties on the basis of the Vienna Convention and the application of the margin's appreciation as a method of interpretation or a method of reducing cultural differences and reducing the moral and legal authority of the International Human Rights Courts, leaving to the State the discretion to limit the exercise of rights and freedoms. It aims to know the rules of interpretation of treaties and the technique of

\footnotetext{
${ }^{1}$ Eneida Orbage de Britto Taquary. Endereço Postal: SMPW Quadra 17 Conjunto 11 Lote 03 Casa B - Park Way - Brasília/DF - CEP: 71741-711. Endereço eletrônico: eneidataquary@yahoo.com.br Doutora em Direito pelo Centro Universitário de Brasilia- UNICEUB, Mestre em Direito das Relações Internacionais pelo Centro Universitário de Brasília-UNICEUB e Mestre em Direito pela Universidade Católica de Brasília-UCB. Professora de Direito, com ênfase em Metodologia da pesquisa, Direito Penal e Processual Penal, Direito Internacional e Direitos humanos e humanitário. Delegada de Polícia Aposentada da Policia Civil do Distrito Federal. Tem experiência na área de Direito, Integrante do Observatório de Segurança Pública do Distrito Federal. Autora dos livros: Crimes Contra os Costumes; Tribunal Penal Internacional e a Emenda Constitucional n 45/2004; Temas de Direito Penal e Direito Processual e Proteção Internacional da Pessoa Humana.Professora de Direito Penal, Direito Processual Penal e Legislação Penal e processual Penal Especial.

${ }^{2}$ Catharina Orbage de Britto Taquary. Endereço Postal: SMPW Quadra 17 Conjunto 11 Lote 03 Casa B - Park Way - Brasília/DF - CEP: 71741-711. Endereço eletrônico: catharinaorbage@yahoo.com.br É Doutoranda em Direito e Políticas Públicas pelo UniCEUB. É bolsista da Coordenação de Aperfeiçoamento de Pessoal de Nível Superior - CAPES para Doutorado em Direito do Centro Universitário de Brasília - UniCEUB. É Mestre em Direito e Políticas Públicas pelo- UniCEUB e pela Universidad del Litoral de Santa Fe - Argentina. Fez intercâmbio em Santa Fé, Argentina para terminar seu Mestrado - Sanduíche como aluna da Universidad del Litoral - UNL. Foi Bolsista da Coordenação de Aperfeiçoamento de Pessoal de Nível Superior para Mestrado e Mestrado Sanduíche - CAPES. É bacharel em Direito pelo UniCEUB. Possui fluência em Alemão, Inglês e Espanhol. Tem proficiência em alemão e espanhol. Foi pesquisadora do Distrito Federal pela Fundação de Apoio à Pesquisa do Distrito Federal - FAP/DF para o curso de Doutoramento em Direito e Políticas Públicas do UniCEUB.
} 
margin of appreciation. The method used is the bibliographical review and the reference to cases appreciated by the human rights courts.

KEYWORDS: Margin of Assessment of the Treaties; Vienna Convention on the Law of Treaties; Pacta Sund Servanda; Judicial Deference; Regulatory Flexibility.

\section{INTRODUÇÃO}

A importância do tema é centralizada na forma como se opera a interpretação dos tratados e a margem que os Estados-partes têm, depois de ratificá-los, em aplicá-los imediatamente, ou então adequar a sua legislação para aplicá-los, independentemente da legislação interna.

A Convenção de Viena sobre o Direito dos Tratados estabelece regras e princípios para a sua interpretação, baseados fundamentalmente no princípio da boa-fé, na melhor proteção do direito pleiteado (pro homine) e no pacta sund servanda, para todos os tratados e em especial para os Tratados de Direitos Humanos e Humanitários, os quais possuem cláusulas que ao serem traduzidas podem oferecer uma contradição entre o que foi discutido e aprovado e o que foi traduzido e escrito no Estado signatário da Convenção. Nesta seara encontra-se a importância do tema.

Este artigo tem por objetivo conhecer as regras de interpretação dos tratados baseadas na Convenção de Viena sobre o Direito dos Tratados e identificar os dois elementos principais: a deferência judicial e a flexibilidade normativa da margem de apreciação, como técnica de tomada de decisão ou método de reduzir as diferenças culturais, determinando uma diminuição da autoridade moral e jurídica dos Tribunais Internacionais de Direitos Humanos, deixando ao Estado a discricionariedade de limitar o exercício de direitos e liberdades.

A metodologia a ser utilizada na análise deste artigo será a revisão bibliográfica, bem como o exame aos casos apreciados pelos Tribunais de Direitos Humanos, quais sejam o europeu e o interamericano.

\section{INTERPETAÇÃO DOS TRATADOS}

No âmbito internacional os Estados devem observância a Convenção de Viena sobre Direito dos Tratados, a qual estabelece cláusulas de como interpretá-lo. A priori, obriga apenas aos Estados-partes e não outros órgãos ou organismos internacionais, como os sistemas normativos de direitos humanos. 
Todavia, a jurisprudência construída no bojo das Cortes de Direitos Humanos tem utilizado as regras de interpretação prevista na Convenção de Viena sobre o Direito dos Tratados, o que tem produzido a adoção de três princípios basilares: (I) pacta sunt servanda; (II) os tratados devem ser interpretados de boa-fé; e (III) o princípio da maior efetividade na proteção, pro homine.

Poder-se-ia mencionar um quarto princípio, o qual decorre do pacta sunt servanda que é a responsabilidade internacional do Estado por atos e omissões (atos ilícitos) cometidos por quaisquer de seus poderes ou órgãos em violação às obrigações internacionais.

Pacta sund servanda é o primeiro e mais importante princípio de interpretação de tratados. Por meio dele, fica normatizado o dever de cumprir as cláusulas de um tratado que foi assinado e ratificado pelo Estado-parte, ou simplesmente assinado, sejam tratados de forma solene ou de forma simplificada. Contudo, não poderia ser diferente.

Ao negociar as cláusulas de um tratado observa-se que o Estado tem a oportunidade de se manifestar no sentido de se aderir ou não ao que está sendo pactuado. Esse momento de negociação do tratado é deveras importante porque entre a assinatura e a ratificação pode decorrer lapso de tempo prejudicial aos objetivos do tratado ou pode ocorrer morosidade no âmbito interno para que o mesmo seja ratificado, frustrando a entrada em vigor do mesmo, fato esse que no Brasil pode ser exemplificado com a ratificação da Convenção de Viena sobre Direito dos Tratados datada de 1969 e somente ratificada pelo Brasil em 2009, logo quarenta anos depois, pelo Decreto 7.030, de 14 de dezembro de 2009 (ALMEIDA. PEREIRA, 2015. p. 171-197).

Nessa linha de raciocínio podem-se diferenciar os tratados que têm forma solene e, que, portanto somente entrarão em vigor com a ratificação, apesar de ter sido assinado o compromisso de ratificação pelo Estado, e os que se consolidam com a simples assinatura de compromisso, os denominados tratados de forma simplificada ou executive agreements. Somente os primeiros interessam para a análise, haja vista que os Tratados de Direitos Humanos e Humanitários trazem cláusulas facultativas que necessitam também de ratificação.

O Estado ratifica o tratado e as cláusulas facultativas submetendo-se a jurisdição da corte internacional criada no bojo do respectivo tratado, ou então ratifica o tratado e posteriormente a cláusula facultativa, conforme ocorreu no Brasil com a Convenção Americana de Direitos Humanos. 
Aderindo, mediante a assinatura do compromisso de ratificar e o ratificando, não há, posteriormente, como legar incompatibilidade com a legislação nacional, salvo os casos previstos na própria Convenção de Viena sobre Tratados, que evidencia os vícios do consentimento estatal, como o erro, dolo, coação ou outras formas de uso da força por parte de um dos Estados negociadores das cláusulas do tratado (Convenção de Viena sobre o Direito dos Tratados, 2015).

A modificação de situação que impeça a ratificação proveniente de caso fortuito ou de força maior que implique aplicação do princípio expresso no enunciado rebus sic stantibus, impossibilidade superveniente de cumprimento, e ainda nas hipóteses em que o tratado admita a denúncia as suas cláusulas ou a renúncia (Convenção de Viena sobre o Direito dos Tratados, 2015).

Assim, a assinatura do compromisso em ratificar o tratado implica a não realização de atos que possam ilidir os efeitos dele decorrentes, na linguagem da Convenção de Viena, em seu artigo 18, um "Estado é obrigado a abster-se da prática de atos que frustrariam o objeto e a finalidade de um tratado” em duas hipóteses (Convenção de Viena sobre o Direito dos Tratados, 2015):

a) tiver assinado ou trocado instrumentos constitutivos do tratado, sob reserva de ratificação, aceitação ou aprovação, enquanto não tiver manifestado sua intenção de não se tornar parte no tratado; ou

b) tiver expressado seu consentimento em obrigar-se pelo tratado no período que precede a sua entrada em vigor e com a condição de esta não ser indevidamente retardada.

Do disposto acima se depreende que a Convenção não previu expressamente um critério de interpretação das cláusulas convencionais, e que o critério gramatical ou literal é insuficiente, para determinar o significado e alcance da expressão "atos que frustrariam o objeto e a finalidade de um tratado” (Convenção de Viena sobre o Direito dos Tratados, 2015).

O significado da expressão resulta da conjugação do princípio da boa-fé que se consolidou com as discussões travadas na $5^{\mathrm{a}}$ sessão da Comissão de Direito Internacional de 1953, na $8^{\mathrm{a}}$, em 1956; na $17^{\mathrm{a}}$, em 1965 ; e na $18^{\mathrm{a}}$, em 1966.

Os argumentos de que a expressão deveria ser interpretada como atos calculados praticados pelo Estado no sentido de obstar a finalidade e o objeto do tratado foi a que se consolidou, em que pese ter havido muitas discussões sobre as expressões inglesa (acts calculated to) e francesa (acts de nature a) e ainda tendant a e tending to, que foram necessárias 
para ao final se estabelecer um critério objetivo na definição da expressão, subtraindo-se da cláusula os elementos subjetivos (abster-se de atos calculados para desapontar as expectativas legítimas de seus parceiros) que pudessem trazer dificuldade ainda maior que a existente (Convenção de Viena sobre o Direito dos Tratados, 2015).

A obrigação acima perdura até a notificação a todos os Estados-partes da decisão de não ratificação: a retirada de sua assinatura nos tratados normativos ou a manifestação por qualquer meio de sua vontade em não mais fazer parte do tratado. Caso contrário, a assinatura do tratado normativo continua a produzir os efeitos do artigo 18, sem termo final, ressaltando os tratados em forma simplificada, cujos efeitos se perfazem com a assinatura.

Em relação aos tratados de direitos humanos ou humanitários a assinatura representa uma obrigação legal e moral de ratificação, que poderá comprometer o país não apenas no cenário internacional, mas também perante seu povo, criando conflitos na jurisdição doméstica. O contrário também pode ser prejudicial à nação, quando o país já ratificou o tratado e ainda não internalizou a lei ou não programou as políticas públicas dele advindas.

O Brasil adotou a Convenção de Palermo, mas somente operou modificação na legislação em 2012, criando conflitos entre o conceito de crime de quadrilha ou bando e o de organização criminosa.

Até 2012, havia apenas o conceito de quadrilha e o supremo não autorizava o uso do conceito de organização criminosa oriundo da Convenção referida com fundamento no princípio da reserva legal. Observe-se que no caso, a Convenção de Palermo já havia sido ratificada. A ratificação das cláusulas que criam os Sistemas de Direitos Humanos mudou de natureza jurídica, de ratificação voluntária passaram a ratificação obrigatória.

A Convenção de Viena estabelece em sua cláusula 31, alínea III que os tratados devem ser interpretados de boa-fé e consoante o contexto, objetivos e finalidade do documento (Convenção de Viena sobre o Direito dos Tratados, 2015).

A boa-fé como princípio de interpretação exige que o Estado adote duas posições frente às cláusulas de qualquer tratado: que não descumpra o tratado alegando ser incompatível com a legislação interna e que utilize os elementos negociados na elaboração das cláusulas do tratado, desde sua assinatura até sua conclusão, para interpretá-lo, evitando atos que frustrem o objeto ou finalidade do tratado, como discutido acima (Convenção de Viena sobre o Direito dos Tratados, 2015). 
Ao lado da regra geral de interpretação prevista no artigo 31 da referenciada Convenção, o artigo 32, estabelece meios suplementares de interpretação, referindo-se a trabalhos preparatórios de tratado e as circunstâncias de sua conclusão, como o objetivo de confirmar o sentido do vocábulo, decorrente da interpretação, ou então determinar o sentido, em face de ambiguidade do termo ou de obscuridade ou ainda em razão de resultado que é manifestamente absurdo ou desarrazoado (Convenção de Viena sobre o Direito dos Tratados, 2015).

A regra do artigo 32 da Convenção de Viena sobre o Direito dos Tratados é necessária e importante porque confirma a dificuldade em se estabelecer regras obvias no bojo dos tratados, sejam eles normativos de direitos humanos ou não (Convenção de Viena sobre o Direito dos Tratados, 2015).

No caso de interpretação de tratados de direitos humanos há consenso entre os sistemas normativos regionais de direitos humanos de que devem ser observadas as regras de interpretação constante da Convenção de Viena, conforme ficou assentado no caso Rantsev v. Cyprus e Russia, onde o TEDH procedeu à interpretação extensiva do conceito de escravidão e servidão, para incluir o tráfico de pessoas e se confirmou, de forma literal, a adoção da interpretação proveniente da Convenção acima mencionada (Tribunal Europeu de Direitos Humanos, 2018).

Na decisão, o referido órgão jurisdicional internacional declara a necessidade de se fazer uma interpretação calcada no princípio pro homine, que impõe a interpretação que resulte na maior efetividade de proteção ao indivíduo, estabelecendo a coerência com outros instrumentos internacionais de mesma natureza, implicando interpretação sistemática e evolutiva no sentido de que cláusulas do tratado deixem de ser preceitos normativos abstratos, confundidos com objetivos e finalidades do mesmo (Tribunal Europeu de Direitos Humanos, 2018)..

No caso Tyrer v. United Kingdom, também apreciado pelo TEDH, que se refere à necessidade de se delimitar o sentido de tortura e de penas ou tratamento desumano ou degradante, que não estava explicitado na Convenção, e que, portanto necessitava de uma interpretação à luz de outros instrumentos internacionais, ficou evidenciada a integração dos vários instrumentos internacionais, e no caso Soering v. United Kingdom a necessidade de salvaguardas que foram exigidas pelo TEDH dos EUA, visando à extradição de Soering, porque 
havia o risco de condenação à pena de morte, que se caracteriza pelo TEDH, como pena cruel (Tribunal Europeu de Direitos Humanos, 2018)

A partir do caso acima o TEDH definiu dois critérios para a análise de casos de tortura e de aplicação de penas desumanas e degradantes, o critério da intensidade do sofrimento e o critério de apreciação relativa.

Em relação ao primeiro, é necessário que se tenha um mínimo de gravidade e de sofrimento físico e mental independentemente da motivação do ato, excluindo os maus tratos, que segundo a Corte não caracteriza tortura, sendo categorias diferenciadas.

A tortura também não se confunde com o tratamento desumano e degradante. O tratamento desumano é o que causa humilhação e desumanização e tem sido utilizado pelo TEDH como condutas que revelam abuso de poder, e a vítima está subordinada a esse poder (Tribunal Europeu de Direitos Humanos, 2018).

Já na expressão de tratamento degradante há o entendimento que se aplica apenas as condições penitenciárias ou de detenção provisória (Tribunal Europeu de Direitos Humanos, 2018).

O Tribunal Europeu de Direitos Humanos consolidou a interpretação de suas cláusulas com base nos princípios da boa-fé; da integração dos diversos documentos internacionais como métodos de interpretação supletivos determinando uma interpretação teleológica e sistemática, e ainda no princípio pro homine ou princípio da regra mais favorável ao ser humano (Tribunal Europeu de Direitos Humanos, 2018).

A Corte Interamericana de Direitos Humanos também tem ratificado sua posição de interpretar as suas cláusulas segundo a Convenção de Viena sobre Direito dos Tratados, bem com aplicado o princípio pro homine.

No caso Godínez Cruz Vs. Honduras, a CIDH entendeu que o desaparecimento forçado de pessoas deveria ser entendido de forma integral e fundamentou a sentença também em vários instrumentos internacionais: no relatório do grupo de trabalho sobre Desaparecimentos forçados do Conselho de Direitos Humanos da ONU, com base na Resolução 20 (XXXVI) de 29 de fevereiro de 1980, como uma atitude concreta de censura e repúdio generalizados, inclusive no âmbito universal pela Assembleia Geral (Resolução 33/173 de 20 de dezembro de 1978); nas resoluções do Conselho Econômico e Social (Resolução 1979/38 de 10 de maio de 
1979) e da Subcomissão de Prevenção de Discriminação e Proteção das Minorias (Resolução 5 B(XXXII) de 5 de setembro de 1979) (Corte Interamericana de Direitos Humanos, 2018).

No âmbito regional, a sentença usa como aporte jurídico no sistema regional a Assembleia Geral da Organização dos Estados Americanos e sua Comissão tem exigido dos Estados à investigação de todas as situações para por fim às violações, consoante as seguintes resoluções (AG/RES. 443 (IX-0/79) de 31 de outubro de 1979; AG/RES 510 (X-0/80) de 27 de novembro de 1980; AG/RES. 618 (XII-0/82) de 20 de novembro de 1982; AG/RES. 666 (XIII0/83), de 18 de novembro de 1983; AG/RES. 742 (XIV-0/84) Del 17 de novembro de 1984 e AG/RES. 890 (XVII-0/87), de 14 de novembro de 1987 (Corte Interamericana de Direitos Humanos, 2018).

Nos casos Gomes Lund v. Brasil; Juan Humberto Sanchez v. Honduras; Kawas Fernandez v. Honduras; Lopez Alvarez v. Honduras; Pacheco Teruel e outros v. Honduras; Bueno Alves v. Argentina e muitos outros julgamentos foram reconhecidos os princípios de interpretação acima mencionados e definido o desaparecimento de pessoas como Crime Contra a Humanidade.

No tocante ao meio ambiente, a Corte Interamericana de Direitos Humanos ao examinar casos relativos à proteção do meio ambiente sadio, utilizou o princípio pro homine e a interpretação sistemática e teleológica

Interpretou a Convenção Americana de forma teleológica ao definir que a violação do direito ao meio ambiente sadio, apesar de não formalmente protegido, foi objeto de garantia judicial quando violado pelo Estado perante a Corte Interamericana, e de forma expressa, o que implica dizer que o acesso à justiça em caso de violação ao direito ao meio ambiente sadio não foi regulamentado, mas tem sido objeto de análise, por via oblíqua.

A análise transversal dos direitos ao meio ambiente sadio foi objeto de diversos instrumentos legais na Corte Interamericana de Direitos Humanos, que julgou sete casos, elaborou um relatório temático e concedeu medida cautelar no caso da Usina Hidroelétrica de Belo Monte. Deve ser ressaltado que a Comissão Interamericana de Direitos Humanos elaborou dois relatórios que versam sobre a proteção do meio ambiente sadio nas comunidades indígenas (ARAÚJO, 2018).

A CIDH também ratificou sua posição, já esposada em outros casos, que há uma estreita vinculação dos povos indígenas com suas terras e os recursos naturais ligados a sua cultura que lá se encontravam, bem como os elementos incorporados decorrentes do vínculo 
estabelecido entre eles: terra, recursos naturais e cultura indígena (Corte Interamericana de Direitos Humanos, 2018).

Ratificou, ainda, que "existe uma tradição comunitária sobre uma forma comum da propriedade coletiva da terra, e o sentido de pertencimento não se centra em um indivíduo, mas em um grupo e sua comunidade” (Corte Interamericana de Direitos Humanos, 2018).

Na interpretação das cláusulas da Convenção Europeia de Direitos Humanos e da Convenção Americana de Direitos Humanos, os tribunais respectivos têm buscando determinar conceitos independentes dos conceitos nacionais, mas utilizando métodos e técnicas semelhantes de interpretação. Constata-se que a busca pela efetividade dos tratados tem sido a tônica dos fundamentos utilizados, visando uma interpretação não restritiva (Corte Interamericana de Direitos Humanos, 2018).

As Cortes de Direitos Humanos têm alcançado propósitos semelhantes no tocante à efetividade dos direitos humanos, restando maior discricionariedade aos Estados-partes no sistema europeu que tem buscado o consenso regional, por meio da produção de conceitos comuns, mas sem drásticas interferências na esfera nacional, enquanto no sistema interamericano a interpretação e aplicação das cláusulas têm encontrado fundamento nos instrumentos e tratados do sistema global geral ou especial da ONU e na jurisprudência da Corte Europeia de Direitos Humanos, prioritariamente, e de outras Cortes Internacionais.

Pode-se observar que, aos poucos a $\mathrm{CtDH}$, seguindo os passos da $\mathrm{CEDH}$, tem adotado como método de interpretação a margem nacional de apreciação, margem de controle ou margem de discricionariedade que permite ao Estado-parte na Convenção uma liberdade regrada na aplicação de suas cláusulas, em razão de não haver a possibilidade de se conferir uniformidade a determinados conceitos no âmbito regional, por falta de consenso entre os Estados-partes perante diferenças culturais, étnicas, nacionais ou religiosas, ou ainda sobre a uniformidade de entendimento e aplicação de alguns direitos, como liberdade de expressão, direitos políticos, direitos das crianças e direito a vida privada e intimidade.

A interpretação, realizada em harmonia com os princípios regentes dos sistemas de proteção da pessoa humana, tem conferido credibilidade aos sistemas e impulsionado a participação no cenário internacional de novos atores que tem provocado o ativismo judicial internacional, conferindo aos juízes maior responsabilidade para analisar o conteúdo fático de cada caso, construindo conceitos próprios, sem apego a conceitos nacionais, mas buscando a 
universalidade de direitos e formas mais eficazes de cumprimento das sentenças, o que tem ocasionado a aplicação, em especial no sistema europeu, de margem de discricionariedade deferida aos Estados no cumprimento de suas obrigações positivas.

\section{MARGEM NACIONAL DE INTERPRETACÃO: INTERNACIONALIZACAO DO ATIVISMO}

A internacionalização ou mundialização das fontes do direito é marcada inicialmente na Europa, mas depois transcende as fronteiras europeias, chegando as Américas e a África. Também se alarga com as fontes da Organização das Nações Unidas e as decorrentes de outros documentos internacionais, gerados em outros sistemas de solução de conflitos.

A descentralização das fontes ratifica a característica de que a esfera nacional não é a única esfera de produção do direito, mas os atos das organizações internacionais, dos tratados multilaterais ou bilaterais e outros sistemas criados como desdobramento dos tratados originais.

A privatização tem possibilitado a elaboração de regras de alcance geral que são elaboradas por organismos privados ou escritórios contratados sobre determinados temas específicos, que terão repercussão no âmbito internacional

A necessidade de especialistas decorre desse fenômeno, quando da discussão de temas em fóruns especializados, juntamente com a terceirização, que também tem sido um recurso utilizado pelos organismos internacionais para levantamento de dados que subsidiarão a elaboração de atos normativos.

Nesse caso os Estados não ficam à margem da produção da norma, mas delegam a uma organização internacional, não organizacional ou a um grupo de especialistas o estudo e pesquisas sobre determinados assuntos reconhecendo sua eficácia no âmbito da jurisdição doméstica.

O fenômeno supracitado tem contribuído como incentivo para que os países, que não detém especialistas em certas áreas, tenham um olhar diferente em investimentos tecnológicos e educacionais, porque ficam alijados do processo de elaboração de regras que serão adotadas em seu país, e acabam por não ter domínio sobre os temas. Na maioria das vezes seus representantes são agentes diplomáticos que, apesar de representar o Estado, não possuem participação de qualidade (VARELLA. 2009. p.33). 
A internacionalização, a descentralização e a privatização consolidam o processo, ainda não concluído, iniciado na década de 50, do pluralismo jurídico na área da antropologia jurídica e da sociologia, que analisou a situação jurídica de comunidades coloniais e póscoloniais existentes á margem da ordem jurídica estatal, bem como a relações advindas dessas comunidades na esfera interna e internacional (MAX PLANCK INSTITUTE, 2015).

Ainda, em face da sociologia seria possível analisar, sob a ótica do pluralismo, vários sistemas normativos regentes de comunidades existentes dentro de um Estado, mas que dele se diferenciam constituindo sistemas normativos auto-regulados, em vários níveis e oriundos de autoridades não estatais (LUHMANN, 2017. p.9).

A justificação da aceitação de fontes comuns do direito de qualquer comunidade formada a partir do multiculturalismo e da imigração, em especial na comunidade europeia, encontra respaldo na teoria do pluralismo jurídico, na medida em que se atribui o reconhecimento de tais regras de produção do direito, por meio do diálogo que se estabelece entre vários grupos de interesse.

O diálogo, para ser legitimador da democracia e logo das regras de direito estabelecidas, seria atestado pela verdade, a sinceridade, a universalidade e a igualdade de condições dos grupos dialogantes (HABERMAS, 2015, p. 503 - 509).

Observa-se, entretanto, que a produção do diálogo entre comunidades distintas e que desejam ser reconhecidas por meio desse é obtida por meio da democracia participativa, que se apresenta menos irreal, ainda que não seja o mais perfeito processo, em face da corrupção e da burocracia, do que as regras estabelecidas por Habermas, em razão da dificuldade de transformá-las em procedimento formal, por exemplo, como princípios ou regras objetivas a serem seguidas.

Desta forma, a participação pelo voto ainda se afigura como uma forma democrática de estabelecer o diálogo entre as várias comunidades existentes e distintas, unidas por laços religiosos, culturais, raciais, linguísticos e nacionais, levando-se em conta que nas recentes democracias esse processo também é vulnerável, dada as condições escassas de autodeterminação do indivíduo (WOLKMER.VERAS NETO. LIXA, 2010. p. 99-138).

Essa dicotomia motiva a ideia de que ao lado dos processos formais estabelecidos para a elaboração do direito (o povo é o detentor do poder de dizer o direito segundo os Estados Democráticos de Direito), outros são constatados no dinamismo da vida social, gerando normas, 
que deverão ser reconhecidas pela própria comunidade que as produziu e cujo reconhecimento se dará em outras esferas, de forma a ser constituído como princípio a ser adotado, em âmbito nacional e internacional.

O reconhecimento do direito, produto da vontade popular, por via direita ou indireta, será declarado pelos legisladores, juízes e ainda pela sociedade civil organizada ou por entes privados, cada qual manifestando pelas suas experiências, atribuições, relações de poder e sociais, e os saberes que constituirão as fontes de produção das normas.

Logo, a forma como os saberes jurídicos são construídos serão determinantes para a produção do direito, assim como os saberes históricos, sociais, religiosos, culturais irão interferir no processo de elaboração deste, como fontes do direito.

A unificação caracteriza um processo brutal de união de sistemas. As relações de integração surgidas do fenômeno do pluralismo com o direito desmistificou, por completo, a hierarquia contínua e linear das leis, expressão de uma pirâmide das normas, acabada e completa, por uma hierarquia descontinuada e por pirâmides inacabadas, em face da criação de tribunais autônomos e que não possuem hierarquia entre si (DELMAS-MARTY, 2004. p. 87111).

A alteração da estrutura piramidal de hierarquia das normas foi substituída pelos processos de integração do direito, moldados pelo pluralismo jurídico, relação essa que é denominada de pluralismo ordenado e que enseja uma série de outros movimentos de produção da norma jurídica, concebidos como unificação por transplantação; a unificação por hibridação; a coordenação por entrecruzamento e a harmonização por aproximação, mas sem respeitar o multiculturalismo, e as expressões do pluralismo jurídico, porque une sistemas sem identidades (DELMAS-MARTY, 2006. p.70-76).

A unificação por transplantação sobrepõe um sistema jurídico sobre outro independentemente de sua identidade. A unificação por hibridação aproxima dois sistemas por reciprocidade, sendo que um deles é modificado para adotar regras jurídicas de outro (DELMAS-MARTY, 2006. p.70-76).

Através do diálogo entre diferentes instâncias que têm como função aplicar a lei ao caso concreto, juízes nacionais, internacionais, estrangeiros ou instâncias quase judiciais fomentam a interação que é possível por meio da coordenação por entrecruzamento.

A troca de experiências e de entendimentos possibilita entre os sistemas o conflito de jurisprudências e torna possível o exame sobre valores comuns que poderão contribuir para 
edificação de sistemas não hierarquizados, mas que comungam desses valores, alterando a posição da jurisprudência sobre determinado fato, na jurisdição doméstica, e desenvolvendo argumentos e olhares distintos do que tradicionalmente seriam adotados.

A harmonização por aproximação, como processo de integração dos sistemas jurídicos, possibilita que a ausência de identidade entre os sistemas não seja óbice para a interação, mas que sejam harmonizados a partir de tipologias compatíveis entre sistemas nacionais e internacionais (DELMAS-MARTY. 2006. p.70-76).

Os processos acima referenciados implicam ordenação do pluralismo diversamente daquela concepção clássica, determinada por um sistema hierarquizado e verticalizado. O sistema atualmente se desenvolve em todas as formas e busca a expressão dos diálogos estabelecidos em diferentes grupos, e em diferentes instâncias, mas de forma ordenada. Essa ordenação do pluralismo é necessariamente concebida pelos conceitos reguladores e ainda numa fase posterior pela definição do aparelhamento, por meio do qual será feito o acompanhamento da evolução e do controle (DELMAS-MARTY. 2006. p.70-76).

Os conceitos reguladores são mecanismos jurídicos utilizados em processos de interação das normas jurídicas internacionais que terão a finalidade de estabelecer ajustes para a harmonização do direito, em âmbito nacional, regional ou mundial, observados os modos de distribuição de competências em face dos órgãos ou organismos que irão realizar a transposição das normas internacionais para o plano nacional ou para o plano de outra instância judicial (DELMAS-MARTY. 2006. p.70-76).

Os mecanismos acima referenciados se afiguram como doutrinas ou princípios que devem ser observadas quando da transposição de normas internacionais para outros sistemas normativos, como o princípio da subsidiariedade, que possibilita aplicação de normas oriundas de um tratado ratificado pelo Estado-parte sem ferir as disposições constantes daquele e sem que haja o ferimento de direitos e liberdades expressos no âmbito da jurisdição doméstica.

O principio da subsidiariedade, na esfera do pluralismo jurídico, permite que o Estadoparte em um tratado incorpore suas cláusulas, mas possa observar um espaço normativo quando da transposição deste para a esfera nacional, observando o multiculturalismo, em especial no tocante aos direitos humanos. Esse espaço normativo foi denominado de margem nacional de apreciação ou margem europeia de controle, que convalida o entendimento de que o juiz 
nacional que deverá interpretar e aplicar o dispositivo tenha maior conhecimento da realidade de seu país onde haverá a transposição (DELMASMARTY. 2006. p.70-76).

\section{A DOUTRINA DA MARGEM DE APRECIAÇÃO}

A doutrina da margem de apreciação instiga no âmbito do direito internacional a discussão sobre a natureza das decisões dos tribunais no âmbito internacional, se deveriam adotar um papel centralizado ou descentralizado, importando em maior ou menor intromissão na esfera da jurisdição doméstica, a partir da solução adotada em casos judiciais internacionais, apresentando-se como uma metodologia de interpretação ou tomada de decisão (MARINHO, 2015. p.137-149).

Na adoção da teoria, dois elementos principais podem ser identificados: a deferência judicial e a flexibilidade normativa. O primeiro refere-se à deferência que é atribuída aos Estados-partes em uma convenção de como cumprir suas obrigações de direito internacional.

O estado tem discricionariedade para implementar obrigações ou cumprir decisões oriundas de cortes internacionais porque tem melhor conhecimento das suas realidades sociais e poderá escolher como fazê-las otimizando a eficácia da medida.

O segundo refere-se à possibilidade dos Estados terem liberdade em disciplinar legislativamente sobre as decisões dos tribunais, porque as normas sujeitas à margem de discricionariedade são normas abertas ou instáveis, porque permitem uma interpretação ampla ou interpretação analógica.

No âmbito dos tratados de direitos humanos, a margem nacional de apreciação, margem de controle ou margem de discricionariedade constitui método hermenêutico de interpretação das cláusulas da CEDH e da CIDH em razão das diferenças culturais, sociais, étnicas e religiosas que estão abrigadas sobre o mesmo direito regional e que merecem acolhimento pelos tribunais regionais de direitos humanos.

No TEDH a doutrina da margem de apreciação foi desenvolvida para aplicação nos casos de proibição à discriminação; casos de decretação do estado de emergência, ocasião em que os direitos da CEDH poderiam ser suspensos; e referente às cláusulas de acomodação ou limitação (que permitem a derrogação de direitos), que tratam dos direitos à privacidade e a família, artigo $8^{\circ}$; a liberdade de religião, expressão, assembleia e associação, bem como a 
liberdade de movimento ou resistência, artigo $2^{\circ}$ do quarto protocolo (SHANY, 2005. p. 907940).

As restrições aos direitos humanos que poderão ser realizadas pelos Estados-partes na CEDH, quando da aplicação da margem de apreciação, referem-se aos direitos coletivos, a segurança pública, a segurança nacional, a preservação da ordem política e econômica, o que é salutar para uma sociedade democrática (SHANY, 2005. p. 907-940).

O reconhecimento de direitos para minorias étnicas e culturais e outros grupos não tem sido problema para as cortes regionais de direitos humanos, mas sintetizar esses direitos em fórmulas uniformes e aplicáveis a todos os Estados-partes na Convenção, de forma a se obter um consenso tem sido a dificuldade encontrada, porque há necessidade de se construir uma interação entre o direito assegurado na decisão do tribunal e a possibilidade dele se tornar efetivo no âmbito interno.

O diálogo estabelecido entre a corte regional e o Estado-parte é essencial na aplicação do método da margem nacional de interpretação. Obviamente além de ter ratificado a Convenção é necessário que o Estado se comprometa a cumprir a decisão e logo torná-la efetiva. É o estado que deverá adaptar a sua legislação e realizar políticas públicas para garantir efetividade ao direito, daí conferir a ele uma margem de liberdade para implementar, segundo sua realidade social, os direitos garantidos, de forma razoável, sem procrastinação.

A aplicação da margem nacional de apreciação pelo TEDH foi aproveitada do direito francês, na interpretação do artigo15 da CEDH, com referência a suspensão de direitos individuais em face da manutenção da ordem pública e posteriormente, em 1968, num caso envolvendo a Bélgica, quando expressamente o TEDH reconheceu seu caráter complementar à jurisdição estatal, e ainda a possibilidade de situações sociais serem melhor avaliadas pelo Estado, que vivencia a realidade, e não pela Corte, mas com observância dos limites estabelecidos na CEDH (DELGADO, 2011, p. 107-135).

A margem nacional de apreciação foi construída e consolidada desde a década de sessenta quando a CEDH reconheceu no caso Lawless v. Irlanda, a margem de liberdade para o estado proteger a nação, mediante limitação de direitos individuais, sem que essa limitação se constituísse em violação as cláusulas da CEDH, seguidos dos casos De Wilde, Ooms et Versyp v. Bélgica, datado de 1971, caso Handyside v. Reino Unido, datado de 1976, discutiuse o conceito de moral e julgou-se de forma inédita um caso de liberdade de expressão. 
No caso Wilgrove v. El Reino Unido, de 1969 houve recusa de fornecimento de certificado de um filme considerado atentatório a moral e bons costumes restringindo o direito à liberdade de expressão, o qual é mencionado na doutrina como o caso emblemático que consolidou o método de interpretação da margem nacional de apreciação no TEDH, ora referente ao exame de suspensão geral de direitos coletivos, ora analisando restrições específicas a direitos individuais.

São exemplos mais atuais e não menos polêmicos e que se referem à autodeterminação sexual e a homoparentalidade os casos, respectivos, Goodwin e I v. Reino Unido e Frette v. França, julgados em 2002.

No primeiro, o TEDH mudou o entendimento esposado nos casos Rees v. Reino Unido, datado de 1986, Cossey v. Reino Unido, datado de 1990, B. v. França, datado de 1992, Sheffield e Horsham v. Reino Unido, datado de 1998; ao admitir o reconhecimento de nova identidade aos transexuais ao proceder à mudança de sexo, que anteriormente havia sido considerado pelo TEDH, como um assunto sem consenso, e logo sujeito a margem de apreciação. No segundo caso, Frette v. França, datado de 2002, houve autorização da margem de apreciação no caso de adoção de uma criança por um casal homossexual.

No SIDH, a margem de apreciação foi utilizada de forma inédita na Opinião Consultiva $n^{\circ} 4$ de 1984 (OC 4/84), que teve por objeto solicitação da Costa Rica, quanto à compatibilidade da proposta de emenda de modificação das regras de aquisição da nacionalidade por naturalização às cláusulas da Convenção Americana, em especial ao direito à nacionalidade e ao princípio da não discriminação (CORRÊA. 2014. p.268-270).

As novas regras constitucionais costarriquenhas, se aprovadas, implicariam endurecimento de regras de aquisição da nacionalidade por naturalização, com aumento de prazos de residência para solicitar a naturalização, bem como a exigência de saber ler, falar e escrever em espanhol, além de submeter-se a um exame sobre a história e valores do país (CORRÊA. 2014. p.268-270).

Na análise, a CIDH definiu a nacionalidade como “o elo político e legal que liga uma pessoa a um determinado Estado com o qual se conecta através de laços de lealdade e fidelidade, proporcionando-lhe proteção diplomática por parte daquele Estado” e considerou que a matéria era da esfera da jurisdição doméstica do Estado Costarriquenho, aplicando a margem nacional de apreciação (CORRÊA. 2014. p. 268-270). 
Nessa seara também é relevante à Opinião Consultiva ${ }^{\circ}$ 6, de 1986, onde a CtDH estabelece o conceito de lei como ato normativo endereçado ao bem comum, emanado do Poder Legislativo democraticamente eleito e promulgado pelo Poder Executivo, enquanto a TEDH, decidiu no caso Sunday Times c Reino Unido, que o conceito de leis deve ser interpretado consoante o sistema jurídico existente, isto é levando-se em conta o órgão ou Poder com competência para elaborar a lei, na forma da Constituição ou de outros instrumentos normativos; a carta de direitos decorrente da fórmula política adotada, e os mecanismos de sua efetividade.

Apesar de se constituir num método realista de se buscar a efetividade das decisões judiciais internacionais sobre tema controvertido de direitos humanos que envolvam diversidade de pessoas e de realidades, a margem de discricionariedade atribuída aos Estadospartes se afigura como um voto de confiança dado pelas cortes regionais de direitos humanos, porque os mecanismos de controle da implementação dos direitos humanos, decorrentes das decisões judiciais internacionais são precários em todos os sistemas.

Essa precariedade no monitoramento da implementação dos direitos assegurados pela decisão judicial internacional tem exigido das Cortes Internacionais parâmetros de limitação para a aplicação da margem nacional de apreciação.

O Estado-parte na Convenção não está livre para apreciar se vai ou não garantir o direito. Ele deve apenas ponderar sobre como irá implementar o direito, cessando a violação, segundo suas realidades sociais e culturais, cumprindo a decisão da corte internacional a que se obrigou por manifesta vontade, decorrente de sua soberania e autodeterminação.

Esses limites inicialmente são fixados pelo próprio texto das Convenções, que exigem, quando da ratificação, que os Estados-partes realizem ações no sentido de conformar seu ordenamento jurídico segundo os direitos previstos no instrumento, porque reconhecem direitos a todas as pessoas, independente da jurisdição a que estão sujeitas, por força do artigo $1^{\circ}$ da CEDH. No mesmo sentido, as cláusulas 1 e 2 da CADH dispõem no sentido de que o Estado deve proceder à criação legislativa ou outras ações que visem à efetividade dos direitos e liberdades previstos na CADH.

A efetividade dos direitos e liberdades não significa apenas a mudança da legislação, mas também a criação de instrumentos normativos que tenham por objeto ações afirmativas 
que estabeleçam as ações que efetive os direitos. Não basta o aporte jurídico. É necessário que se desenvolvam ações para cessar a violação de direitos e liberdades.

A margem nacional de apreciação como método de interpretação, técnica de tomada de decisão ou método de reduzir as diferenças culturais determina uma diminuição da autoridade moral e jurídica dos Tribunais internacionais de direitos humanos, deixando ao Estado a discricionariedade de limitar o exercício de direitos e liberdades.

A universalidade, a interdependência e a indivisibilidade dos direitos humanos são características que transformam os tratados de direitos humanos em tratados vivos, quando as decisões judiciais internacionais prestigiam os direitos e liberdades. A aplicação da margem de apreciação vai corroendo a possibilidade dos juízes de cortes internacionais, pelo exame reiterado de determinadas matérias, analisarem o conjunto probatório com cautela e modificarem suas posições perante um mundo marcado pela diversidade, como no caso de homoparentalidade.

O sistema normativo global e regional fica privado, com a adoção da margem de apreciação, de travar diálogos sobre hard cases, devolvendo a esfera da jurisdição doméstica o exame da matéria, sem que se possibilite uma discussão global dos temas e provoque mudanças de posições.

O argumento de que a margem de apreciação propicia segurança jurídica perante os Estados-partes na discussão das causas é falacioso, porque dentre os critérios de admissibilidade da demanda perante os tribunais de direitos humanos está o esgotamento das instâncias na jurisdição doméstica, o que denota que a questão já fora discutida ou há morosidade injustificável no julgamento.

Além dos argumentos acima, outro de relevante importância é a necessidade da comunidade dos Estados-partes em tratados de direitos humanos efetivamente monitorar o cumprimento das sentenças, de forma a tornar pública a responsabilidade moral e jurídica dos Estados que implementam, tardiamente, direitos reconhecidos nas decisões judiciais internacionais.

\section{CONCLUSÃO}

O sistema do direito internacional, diferentemente dos sistemas jurídicos clássicos, não possui como característica comum uma só fonte ou uma fonte que seja considerada 
hierarquicamente superior à outra e que determine uma hierarquia piramidal. As fontes das regras internacionais surgem em face de uma série de fatores, como os interesses políticos e econômicos das nações envolvidas, as pressões de organismos internacionais.

Tradicionalmente, admite-se que a fonte de produção do direito internacional compreenda o consentimento dos Estados ou organizações internacionais que manifestam seu poder soberano por intermédio da ratificação de tratados.

Esses tratados têm favorecido o movimento de internacionalização do direito e logo do pluralismo em todas as partes do mundo, com algumas exceções raras, que tem provocado o aparecimento de fontes jurídicas não necessariamente vinculadas exclusivamente ao consentimento dos Estados, mas provenientes de outros organismos internacionais e ainda decorrentes da atuação de indivíduos por meio das organizações não governamentais e da sociedade civil organizada.

A Convenção de Viena Sobre Direito dos Tratados por meio dos princípios da boa-fé, na melhor proteção do direito pleiteado (pro homine) e no pacta sund servanda, tem contribuído para a melhor interpretação dos tratados em geral e especialmente para os Tratados de Direitos Humanos e Humanitários.

A dificuldade de uniformizar um sentido na interpretação de cláusula do tratado de direitos humanos, por meio de uma decisão judicial, para grupos diversos, é o fato gerador da margem de apreciação. Ela se afigura com mais propriedade quando o tema, a ser analisado pelos juízes das cortes regionais de direitos humanos, versa sobre direitos polêmicos, como minorias étnicas, propriedade, direito indígena, liberdade de expressão, intimidade, relações homoparentais e vida privada.

A teoria da margem de apreciação ou de controle permite que o Estado decida pelos mecanismos de implementação dos direitos humanos na esfera de sua jurisdição doméstica, decorrentes das decisões judiciais internacionais, permitindo certa discricionariedade no cumprimento das sentenças internacional, em sua totalidade.

A técnica ou método acima está assentado em dois requisitos: A deferência judicial e a flexibilidade normativa. A deferência, como o nome indica, se refere à discricionariedade atribuída aos Estados-parte em uma convenção de como implementar obrigações ou cumprir decisões oriundas de cortes internacionais porque tem melhor conhecimento das suas realidades sociais e poderá escolher como fazê-las otimizando a eficácia da medida. A flexibilidade se 
refere a forma que o Estado-parte no tratado irá adotar para legislar sobre a matéria no âmbito da jurisdição doméstica ou tornar possível a adequação da matéria frente aos sistema legal estatal.

A margem de apreciação ou margem de controle como técnica de interpretação ou método de reduzir as diferenças culturais, realiza dois efeitos: por um lado determina uma diminuição da autoridade moral e jurídica dos Tribunais internacionais de direitos humanos, deixando ao Estado a discricionariedade de limitar o exercício de direitos e liberdades, e por outro, é instrumento impulsionador da participação estatal na construção da compliance frente as decisões internacionais dos Tribunais de Direitos Humanos e consequentemente no fortalecimento dos Sistemas normativos Internacionais de Direitos Humanos.

\section{REFERÊNCIAS}

ALMEIDA, Paula Wojcikiewicz and PEREIRA, Maíra Fajardo Linhares. Revisitando os efeitos da assinatura de um tratado internacional: da obrigação de boa-fé à sujeição internacional do estado. Rev. direito GV [online]. 2013, vol.9, n.1, pp. 171-197. ISSN 18082432. Disponível em http://dx.doi.org/10.1590/S1808-24322013000100007.Acesso em $\underline{10.11 .2015}$

ARAÚJO, Luiza Athayde de. Direito ao meio ambiente sadio como um direito humano: uma análise da jurisprudência dos sistemas regionais de proteção de direitos humanos. Artigo sob a orientação de Danielle de Andrade Moreira. Disponível em http://www.pucrio.br/pibic/relatorio_resumo2011/Relatorios/CSS/DIR/DIR_Luiza_Athayde.p df. Acesso em 20.1.2018

CEDH.CASE-LAW.

Disponível

em https://www.echr.coe.int/Pages/home.aspx?p=caselaw/analysis\&c=\#n1347528850996_pointe r. Acesso em 1 de fevereiro de 2018

CORRÊA, Paloma Morais. Corte Interamericana de Direitos Humanos: Opinião Consultiva 4/84 - A Margem de Apreciação Chega à América. Revista de Direito Internacional. Brasília, v.10, n 2. 2014.

COSTA RICA.CORTE INTERAMERICANA DE DERECHOS HUMANOS CASO COMUNIDAD INDÍGENA XÁKMOK KÁSEK VS. PARAGUAY SENTENCIA DE 24 
DE AGOSTO DE 2010 (FONDO, REPARACIONES Y COSTAS) Disponível em http://www.corteidh.or.cr/docs/casos/articulos/seriec_214_esp.pdf Acesso em 20.1.2018 CVDT-CONVENÇÃO DE VIENA SOBRE DIREITO DOS TRATADOS. Arts.43-52. Disponível em http://.un.org/law/ilc/. Acesso em 10.11.2015

DELGADO, Francisco R. Barbosa Delgado. Los límites a la doctrina del margen nacional de apreciación en el Tribunal Europeo y la Corte Interamericana de Derechos Humanos: intervención judicial en torno a ciertos derechos de las minorías étnicas y culturales. Revista Derecho del Estado n. ${ }^{\circ}$ 26, enero-junio de 2011, pp. 107-135, Electronic copy available at: http://ssrn.com/abstract=1874735

DELMAS-MARTY. Mirreile. Por um Direito Comum. Tradução de Maria Ermantina de Almeida. Prado Galvão.São Paulo: Martins Fontes. 2004.

DELMAS-MARTY, Mireille. Les forces imaginantes du droit (II). Le pluralisme ordonné. Paris : Editions du Seuil, 2006,pp.70-76

HABERMAS, Jiirgen. Between facts and norms: contributions to a discourse theory of law and democracy I. Translation by William Rehg. Jürgen-Habermas-Between-FactsandNorms.pdf Acesso em 10 março de 2015.LUHMANN, Niklas. O Caleidoscópio do Direito. O Direito e a Justiça nos dias e no mundo de Hoje. Lisboa: Almedina. 2007. cap 9.

LIXA, Ivone Morcilo. Pluralismo jurídico: insurgência e ressignificação hermenêutica. In WOLKMER, Antonio Carlos, VERAS NETO, Francisco Q., LIXA, Ivone M. (orgs). Pluralismo Jurídico : os novos caminhos da contemporaneidade. São Paulo: Saraiva, 2010.pp 99-138

MARINHO. Maria Edelvacy Pinto. Processo de internacionalização dos direitos: a criação de um direito comum. NOMOS-Revista do Curso de Mestrado em Direito da UFC. Volume $\begin{array}{lllllll}30.2 & - & & j u l / d e z & - & 2010 / 2 & \text { Disponível }\end{array}$ http://.periodicos.ufc.br/index.php/nomos/article/viewFile/405/387. Acesso em 15 de maio de 2015.

MAX PLANCK INSTITUTE FOR SOCIAL ANTHROPOLOGY. Disponível em http://.eth.mpg.de/3720186/pglp. Acesso em 15 de maio de 2015

VARELLA, Marcelo Dias. Direito Internacional Público. São Paulo. Saraiva: 2009.p.17

SHANY, Yuval. Toward a General Margin of Appreciation Doctrine in International Law? EJIL 16 (2005). 